\title{
Towards a Real Alternative?
}

\author{
Vaughan Rapatahana
}

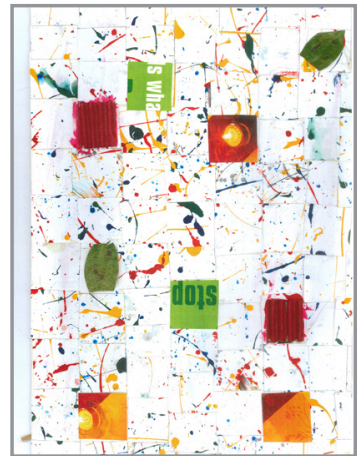

\section{Position paper/Interview practice paper}

\section{INTRODUCTION}

In these days of state-administered and generally well-funded educational vehicles ostensibly heading off on different routes than those travelled by socalled 'mainstream' majority of schools, there was, back in 1977, a significant alternative educational harbinger.

Auckland Metropolitan College (AMC) was the first alternative education secondary school sanctioned and indeed funded by the New Zealand Department of Education. The kaupapa or philosophy for this unique and un-zoned school was based on the concept of a school without walls. This was a site where students wore no school uniforms, had no forms or rigid timetables, and which was run by nonhierarchical school meetings, open to all members of the school's community - thus staff, students, parents, and others.

Students chose which modules they would take during the course of any given year, which were evaluated as seen best by the teacher involved, wherever the class was held - for teachers could be anywhere in the community. Indeed, community service was an expected aspect of student involvement well before national certificate educational achievement (NCEA) credits were awarded for students work across a wide range of interests by tutors, who also deemed a pass, after grading student's work. Students also had to attain a certain number of credits to receive recognition over a year's mahi or work. Auckland Metropolitan College first opened in Vermont Street, Ponsonby and later shifted site to Mt. Eden.

David Hoskins was the originator of the school. I interviewed him about his initial vision behind Auckland Metropolitan College (AMC), as well as its subsequent demise after several negative Educational Review Office (ERO) reports, leading to its ultimate closure in 2001. This latter aspect is particularly well summarised in Karen Vaughan's Daring to be Different: The Rise and Fall of Auckland Metropolitan College (NZ Annual Review of Education 11, 2002).
The especial pertinence of this school to Resource Teachers: Learning and Behaviour (RTLB) - and indeed many of the 'alternative' routes as mentioned above - is this: all RTLB work with students and whanau (family) who are not mainstream-orientated for whatever reason - and there are many - and who could well benefit from a trip away from mainstream education, with its generally examination-orientated, rule-bound ethos. Many of these students do not fit an environment in which many of them have not, and will not, travel far, even if they are still allowed to commute down its avenues.

However, how many of these other routes are actually alternative, as in developing an individual's full potential in different ways other than via strict time-bound lessons across a tight array of topoi? Are there qualitatively different educational routes in Aotearoa/New Zealand or will ever-pragmatic ERO audits and accountants ultimately disavow any such, as happened at Auckland Metropolitan College? Can we ever hope to see alternative schools as exactly that - not as alternatives to a school (such as the cases of several truancy-inspired alternative education sites and so on) - but as state-sponsored alternative schools that do not in some way preach and teach what Ivan Illich deemed the hidden curriculum? This is where the essential norms and mores of a society's dominant culture continue to be maintained, even if theoretically abnegated by the agents of this culture. Auckland Metropolitan College manifestly sped well away from this concept, which, all rather worryingly, led to its ultimate demise.

Thus, alternative education sites, hourua or charter schools, homeschooling options, the Correspondence School, kura kaupapa, designated character section 156 schools and the exponential traffic jam that is communities of learning, and even independent schools, are partially funded by the state.

My question, then, is this; are RTLB actually maintenance agents of the hidden curriculum, rather than true agents of change in New Zealand education? Cannot we seek out and travel down variant, exciting, yet still valid existential, social and 
learning via media for our cohorts of students and their families? I believe that we do require alternative schooling in the essential sense of the term as best stated by David Hoskins in 1975 ... 'is not the organisation of most schools incongruous to learning? For the school cannot primarily be conceived in terms of a set number of buildings, that is geometrical space, or in a given number of time-periods throughout the day. Rather the school corresponds to the community as such' (Reflections upon a school, NZPPTA Journal, October). We need educational panaceas such as Auckland Metropolitan College once offered.

\section{INTERVIEW WITH DAVID HOSKINS}

The Auckland Metropolitan College opened in 1977. You were the founder. Tell us something about your own background, with particular reference to your (then) philosophy of education. How did you actually manage to get the school underway?

I became interested in the functions of schooling when I taught in a public school in Virginia which had only the year before opened after being closed for four years. In the 1960's, I was involved in civil rights actions in Virginia. Local school boards, being pressured to integrate with the 1964 Civil Rights legislation, often simply closed the public schools rather than integrate them. In a certain area in Virginia, the public schools were closed for four years. I taught for a year in such a school, which had only recently re-opened. The school was 90 percent black and each class had a four-year age range. I was also appointed to a school committee to oversee its operation. After one year, I realised that the institution of schooling just did not meet the needs of the students and the local community. So I decided to travel and think about these various issues. And I wound up in NZ.

In considering the relationships between the school, its students and local community, I tried to clarify the values and attitudes engendered within students simply by being part of a school system. And I became interested in a recent development called 'schools without walls'. Schools, which utilized the local community for both its spaces and teachers.

I had studied at a small college in Virginia (hence my knowledge of southern civil rights) where I had a double major in chemistry and philosophy. While in NZ, I decided to pursue the philosophy, always with an eye towards educational issues. When I was tutoring in the philosophy department, I was doing the same in the education department- although I had never taken a paper in education.

In 1974, the National government created the Educational Development Conference. This was a public discussion on the future of education in NZ. I took the opportunity to clarify my educational ideas, wrote a proposal for a 'school without walls' and sent it to the Minister of Education. He replied that he was interested in discussing this further and put me in touch with the Director of Secondary Schools in Auckland. In 1975, a committee was created including 'progressive' educationalists (people like Des Mann and Charmaine Pountney). At the end of the year, it was agreed that a trial school along the lines of my proposal would be established. I had always argued that any trial had to be within the state system and have no financial hurdles to participating as a student. This was accepted. But because of this, and because I had no NZ teaching experience, I could not be the head of the school, nor a staff member unless I went to teachers college, which I did in 1976, with the school starting in 1977.

\section{What were you hoping to achieve with the setting up of the Auckland Metropolitan College?}

I was never in favour of 'alternative schools' as they were generally perceived in those days, that is, places of laissez faire activity where students had no 'rules' or requirements to do anything. Schools like Summerhill. My thoughts were that everyone had to have some structure, but that this structure had to be created by everyone who was a participant.

I had become aware by this time of Illich and the concept of a hidden curriculum. I had come to the same idea that schools, by virtue of their structure, 'taught' students certain values and ways of thinking. The idea of the AMC was to be very clear about these 'hidden structures' and try to create ones that were more 'democratic'.

So the school as it was proposed had about five basic principles which were set out as mission statements. I can't remember them all- and I can't find the early written stuff but they were things like:

- enabling students to be autodidacts, and to actively participate in their own learning

- to have all decisions concerning the school management and operation be set at a school meeting where all, students and staff, had one vote

- to have learning perceived as a community-wide activity, not limited to a particular set of people or buildings.

(We later did untrove the document stating the essential aims of Auckland Metropolitan College. The others were - to develop critical acumen; to develop communication skills; to develop responsibility. Interviewer notes - 2017)

Anyway, these were the reasons why, in its first year, the school was based in an old manual training 
centre in Ponsonby. It was just big enough to have a school meeting, but not to hold all the classes and that there were no forms per se (and as a state school, we still had to operate under that curriculum). Anyone could join a class, so long as they could meet the prerequisites - if any. Indeed, there were no age barriers to anything.

All school rules were created at school meetings and there was a disciplinary committee of two students (elected by the students) and two staff. If a student broke a rule, they came before this committee. But the major argument was that it was a rule broken by someone who had participated in creating them.

The staff were not seen as 'teachers' but facilitators - helping to liaise with the community to provide a range of classes and to also work with the students to see what they were interested in. No student was forced to do anything. When coming from another school, there was always a transition for the student to 'unlearn' certain values and ways of doing things. So there was general room for doing nothing. But the student was not left isolated. This was where the staff came in. Anyway - this was how the school started.

\section{How much of an influence was the work of Ivan Illich in this establishment of such an 'alternative' school in Aotearoa/New Zealand?}

As I said above, Illich's ideas on education reinforced what I was doing. His book Deschooling Society' was a great clarification of the hidden curriculum. But as an influence, Paulo Freire in his 'Pedagogy of the Oppressed', was equal, particularly in terms of how relations between teachers and learners could operate. So, Illich didn't really have much influence directly on the school. His concepts reinforced and helped clarify what I was doing.

Did you actually meet Illich when he was here in 1976 and if so, what were your impressions of him, please?

Unfortunately, I never did meet him. I went to his lectures and taped them.

You stayed with AMC for approximately 18 months. Why did you 'dis-establish' yourself from the school?

As a state school it was operating under the framework of all state schools and their staffing. I didn't have the teaching experience to be the head, just a staff member as mentioned above. So the Board of Governors (we came under Penrose High), appointed Andy Begg. As it turned out, his ideas were directly aligned with Summerhill: very different from the original principles that I set out. I spent two full years teaching, and achieving what I could but there was a clash of educational philosophies involved: obviously an untenable situation, and one I could not win. So I left. And then I spent a few years writing a manuscript on the NZ education system. And here is where Illich had his influence on me, because I established a working relationship with him (via correspondence), where I would send parts of the manuscript for his comments. When I had finished, he said it was a work that needed to be published but as it was specifically focused on NZ, that might be difficult with his publishers. So he gave me the English rights to one of his recent lectures (in German) to use as an introduction and to help get it published in NZ. By this time it was 1981, I think.

Anyway, no NZ publisher wanted it unless I happened to be a university staff member who could set it as a text, but it did make the academic rounds. And in 1982, Ivan Snook, who was NZ's leading philosopher of education and who was setting up a department at Massey in Palmerston North (he had just come from Canterbury), invited me to join him and do a PhD under his supervision. I went down for a year in 1982, but realised it wasn't for me. This was when I became a community worker and tried to use my ideas within the wider community.

\section{Looking back, why do you think Auckland Metropolitan College faltered as an alternative school and finally was wound up in late 2001?}

Because of a loss of focus. When my original principles were lost, they never replaced them. I never liked places like Summerhill because they depended entirely on the personality of the main person like A.S. Neill. I was attempting to create a place in which the personalities were less important than the principles. This was my naivety. But it was also why the school was bound to fail.

Is there any place for a similarly 'alternative' school in Aotearoa/New Zealand education nowadays, given that there are charter schools, home schooling and so on ...?

I'd have to think about this. Do any of the above provide students with the opportunity to participate in the running of the place? I gave the keynote address years ago to the National Homeschooling Association and suggested that they are still 'teaching' a hidden curriculum and to be aware of what it is (it is worth noting that there are now some Designated Character schools in Aotearoa/New Zealand as under section 156, including Ao Tawhiti and Tamariki, in Christchurch: these schools have several parallels to the abiding philosophies behind Auckland Metropolitan College, given that they abide by the state curricula overall. Interviewer notes - 2017). 
Finally, tell us a bit about what you are doing now, out of the education frame of reference. Do you have any regrets about Auckland Metropolitan

College ...?

AMC was a great experience. Even though its principles changed from those I had created, and even though it became something very different, it still provided students with a unique opportunity. My two sons disliked the college they were attending. I'm not sure 'dislike' is something any student at Auckland Metropolitan College over its 25 years would use to describe their experience of it. And that's something.

Thanks, Vaughan, for the opportunity to remember all of this.

There is an interesting and honest set of interviews of AMC staff and students available at: https://www. youtube.com/watch? $v=c J G c v A 2 M R r Y$ Interviewer notes - 2017

\section{AUTHOR PROFILE}

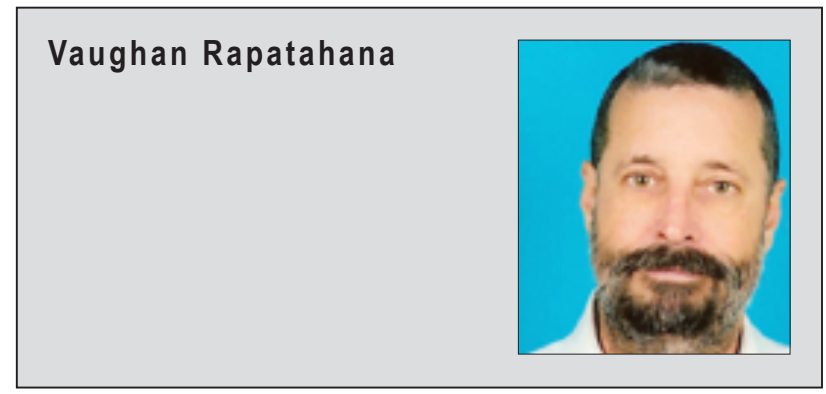

Vaughan Rapatahana is an RTLB in Waikato and attained his PhD from the University of Auckland. He is published widely internationally across several genre. Vaughan won the Proverse Poetry Prize in 2016, the same year his collection Atonement and was nominated for a National Book Award in the Philippines. His NZ Book Council file is here - http://www.bookcouncil.org.nz/Writers/Profiles/ Rapatahana\%2c\%20Vaughan

Email: rtlb.vrapatahana@mi.school.nz 